\title{
SÕNA
}

\section{ETÜMOLOOGILISI MÄRKMEID (XIV)}

\author{
UDO UIBO
}

\section{asima}

$\mathrm{E}$ esti keele seletav sõnaraamat peab verbi asima murdeliseks ja annab selle tähenduseks 'kahmama, krahmama, rabama' (EKSS 1: 158). Suur murdesõnaraamat pakub sama sõna tähenduseks 'kinni haarama, kinni võtma' (EMS I: 472). Ehkki määratlused on lähedased, tundub murdesõnaraamatus kasutatud 'haarama' (resp. 'kinni haarama') universaalsem ja hõlmavam ka seletava sõnaraamatu lausenäidetest lähtudes: Asis 'haaras' tüdrukul ümbert kinni. Asisin 'haarasin' viljakoti sülle. Poisid läksid rüselema, asisid 'haarasid' teineteisel rinnust kinni.

Murdeliselt on asima põhiliselt Kirde- ja Ida-Eesti sõna, mille kompaktne levila ulatub XX sajandi murdekogude andmeil kirderannikult Kodavereni (VMS I: 53). Eesti Keele Instituudi kirjakeele arhiivis pärinevad selle sõna esimesed sedeldused 1930. aastaist kirjanik Leida Kibuvitsalt, kelle sünnikoht Tartumaal Haaslavas jääb asima dokumenteeritud murdelevilast lõuna poole. Tõenäoliselt tänu temale on see jõudnud 1948. aastal „Suure õigekeelsus-sõnaraamatu” I vihikusse (SÕS I: 54 asima haarama, kahmama). Pole välistatud, et seesama sõna on eesti sõnaraamatuis registreeritud juba varem, aga mõnevõrra teistsuguse kujuga. F. J. Wiedemanni eesti-saksa sõnaraamatu teises trükis leidub märksõna azuma all väljend aśjast kińnii a. tähendusega 'eine Sache anfassen, anpacken' ehk siis 'asjast kinni haarama' (Wiedemann 1893: 58). XX sajandi murdeainese põhjal koostatav suur murdesõnaraamat sõna asuma niisugust tähendust ei tunne. Nii jääb Wiedemanni ülestähendus teadaolevalt ainukordseks ja selle tõlgendus vaieldavaks.

Paraku kipub Wiedemanni sõnaraamatu näide sugereerima, et verbid asuma ja asima on ajalooliselt samatüvelised. Soome etümoloogiasõnaraamatud samastavadki need ilma kõhklusteta (SKES I: 26 asea; SSA I: 85 asea). Äsja ilmunud „Eesti etümoloogiasõnaraamat” on ettevaatlikum, jättes siduva etümoloogia esitamata ja märkides üksnes, et asima võib olla häälikuliselt ajendatud keelend või siis samatüveline sõnaga ase, mis ühtlasi tähendab ajaloolist kokkukuuluvust verbiga asuma (EES: 54 asima, 55 asuma). Häälikuliselt ajendatud resp. deskriptiivsõna mõte on ilmselt üle võetud Julius Mägistelt, kes on pidanud eesti verbi asima selle väidetavatest läänemeresoome vastetest tähenduslikult liiga kaugeks (EEW I: 106-107 asima). Pakutud alternatiivne tõlgendus pole aga sugugi parem, pigem vastupidi. Pelk „deskriptiivsõnaks” kvalifitseerimine ei ütle sõna päritolu kohta õigupoolest midagi.

Hilise dokumenteerituse tõttu tekib kahtlus, kas asima ei võiks olla hoopis uuem laensõna. Sobiv lähtekoht leidub saksa keeles, kus verb haschen tähendab 
'(kinni) haarama; kinni krapsama; kinni püüdma' (Tuksam, Muuk 1939: 457). Sõnade häälikuline vastavus on ideaalne: sõnaalguline $h$ jääb Põhja-Eesti murretes edasi andmata, saksa $s c h$ [ธ̌] rahvakeelseks vasteks on $s$ või $s s$ ja järgsilbi $e$ [ə] vasteks $i$. Ka semantiline vastavus on hea, ehkki eesti keelde on üle võetud üksnes tähendus '(kinni) haarama'. Teine, kinnipüüdmise tähendus kajastub Harglast kirjapandud vananenud murdeväljendis `hassõ tegemä 'tagumist paari välja kutsuma'; sõna ass tagumise paari mängu ergutushüüdena on dokumenteeritud ka Kuusalust (EMS I: 478 hass $^{3}, h_{a s s}{ }^{4}$ ). Nende aluseks on saksa verbi käskiva kõneviisi vorm hasch! 'püüa kinni!' ja nimisõna Haschen '(kinni)haaramine; kinnipüüdmine', mis on saksa murretes levinud ka tagaajamismängude, eriti kulli ehk lätsu, aga nagu võib otsustada eesti murdenäidete põhjal, nähtavasti ka tagumise paari mängu nimetusena.

\section{iidne}

Eesti murretest hajusalt registreeritud, kuid tänapäeva kirjakeeles üldlevinud sõna iidne 'ealt väga vana v. ajaliselt väga kauge; igivana, muistne' (EKSS 2: 581), 'igavene; igivana, põline' (EMS I: 892) päritolu käsitledes on meie keeleteadlased seda kõhklematult või kõhklemisi pidanud kokkukuuluvaks sõnadega hiis 'muistsel ajal pühaks peetud mets, salu, kus käidi palvetamas v. ohverdamas' ja hiid 'üleloomulike omaduste ja võimetega inimesekujuline olend; hiiglane' (vrd EEW II: 341; Raun 1982: 17; EES: 90). Torkab aga silma, et soome etümoloogiasõnaraamatu artiklis hiisi leiduvad eesti vastete hulgas küll sõnad hiis ja hiid, aga mitte sõna iidne (SSA I: 162). Sõna iidne kuulumine samasse sõnaperesse ongi küsitav. Esiteks, sõna hiis algab $h$-ga, aga sõna iidne pole $h$-algulisena usaldusväärselt dokumenteeritud. Mulle teadaolevalt esineb $h$-alguline hiidne üksnes Lauri Kettuneni eesti-soome sõnaraamatus (Kettunen 1917: 33), kus $h$ on arvatavasti etümologiseeriva teoretiseerimise tulemus. Ja teiseks, sõnade hiis ja iidne tähendusseos on pigem ebamääraselt assotsiatiivne kui ühemõtteliselt selge.

Sõna häälikkujusse takerdumine ja tähenduse tagaplaanile jätmine on etümologiseerimisel sagedane komistuskivi. Kui aluseks võtta sõna iidne tähendus, näib lugu olevat üsna lihtne. Tsiteerin veel kord seletus- ja murdesõnaraamatut, seekord vajalikke tüvesid sõrendusega esile tõstes: 'e a lt väga vana v. ajaliselt väga kauge; i g i vana, muistne', 'i g a vene; i g i vana, põline'. Lauri Kettuneni eesti-soome sõnaraamat aga annab murdeliseks märgendatud sõna hiidne soome vasteks iänikuinen. Pole raske märgata, et kõigis neis sõnaraamatutes on tähenduse avamisel kasutatud soome-ugri põlistüvest iga 'aeg; vanus' ja selle variandist igi- lähtuvaid sõnu.

Kuivõrd iidne tähendab 'igivana, igipõline', on seda loomulik tõlgendada eesti keeles tekkinud tuletisena iga-tüve variandist igi-. Oletatav muistne tuletis

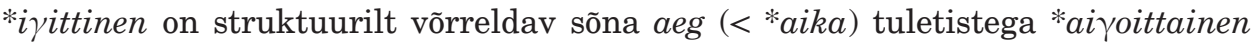
ja *aiyoittinen, millest lähtuvad soome ajoittainen ja eesti ajutine. Tuletises *iүittinen toimusid reeglipärased muutused: hääliku $k$ nõrga astme vaste $\gamma$ kadu

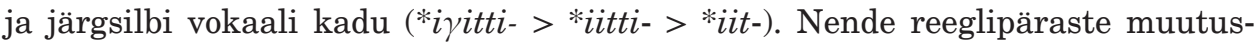
te ootuspärane tulem tänapäeva keeles oleks dokumenteerimata sõnakuju *iitne [`iitne], mida sõnast iidne [`iiDne] lahutab üksnes kukesamm. Selle kukesammu astumise võis tingida asjaolu, et astmevahelduse tõttu $k$-ainese kaotanud iit-tüvi ei seostunud enam olemasoleva tüvevaraga, ja sõna *iitne häälikkuju ühtlustati 
nimetavas käändes sõna raudne $(\leftarrow$ raud $)$ tüüpi tuletiste häälikkujuga. Ühtlustamiseks oli põhjust, sest enamasti langes sisekao tõttu tekkinud konsonantühendi hääldus mõlemal juhul kokku (vrd *iitse [`iitse] ja raudse [`rautse]) ning erandliku ne-liitega ainsuse nimetav oli ainus käändevorm, kus hääldus erines (*iitne [`iitne], aga raudne ['raubne]).

Öeldu taustal pakub huvi haruldane, kahest Viljandimaa kihelkonnast (KJn, Krk) dokumenteeritud murdesõna igitigine 'põline' (VMS I: 84). Selle esiosa igitlähtub arvatavasti samast alusvormist *iүitti- mis sõna iidne tüvi iid-, aga selle vahega, et siin ei ole toimunud astmevaheldust. Murdesõna igitigine (,igiti-igine") on samasugune reduplikatiivkeelend nagu Lauri Kettuneni poolt sõna hiidne tõlkevasteks pakutud soome iänikuinen, ainult et eesti liitsõna esikomponent on tuletatud, mitte lihttüvi nagu soome keeles.

\section{kabuhirm}

Liitsõna kabuhirm 'pöörane, tugev hirm, paanika' (EKSS 2: 23-24) esikomponendi $k a b u$ - tähendus on tänapäeva keele vaatevinklist hämar. „Eesti etümoloogiasõnaraamat" pole sellele siduvat etümoloogiat esitanud, vaid piirdunud tõdemusega, et tüve on samastatud murdesõnaga kabu (omastav kabu) 'kohihärg (harva -oinas, -koer, -kukk); sarvloom, lehm', mida on omakorda samastatud sõnaga kabu (omastav kao) 'kaunis neiu, naine', aga teisalt on arvatud ka, et sõna võib kuuluda kokku verbiga kabisema 'tasast, kerget kobinat v krabinat tekitama' või kablutama 'kergelt ja kiiresti liikuma' (EES: 111). Need suuremalt jaolt Julius Mägiste etümoloogiasõnaraamatu mustandist (vrd EEW II: 635) pärinevad tõlgenduskatsed tunduvad olevat semantiliselt üsna meelevaldsed ja tuginevat üksnes sõnade häälikkuju samasusele või lähedusele.

Eesti liitsõna hämara tähendusega esikomponent muutub selgemaks, kui asja vaadata tähenduse poolelt. Soome keeles tähistab paanikat ehk kabuhirmu liitsõna pakokauhu, mis on moodustatud sõna pakea 'põgeneda, pageda' tuletisest pako 'põgenemine, pagu' ja sõnast kauhu 'hirm'. Erinevalt eesti sõnast kabuhirm on soome liitsõna selge tähendusliku motivatsiooniga: pakokauhu on põgenema, pakku jooksma sundiv hirm. Eesti ja soome liitsõna esikomponente kabu- ja pakovõrreldes näeme, et need erinevad üksnes klusiilide $k$ ja $p$ (eesti ortograafias $b$ ) paigutuse ning selle poolest, et eesti sõna teises silbis on $u$, soome sõnas $o$. Aga on teada, et põhjaeesti $u$ on järgsilpides soome $o$ reeglipärane vaste. Niisiis on eesti sõnas klusiilid lihtsalt kohad vahetanud, ehk teisisõnu, on toimunud nende metatees.

Tekib küsimus, kes siis nende klusiilide kohad vahetas ja kes on selles süüdi, et eesti keeles on paguhirmu asemel kabuhirm. Küsimus on seda enam intrigeeriv, et XX sajandi murdekogud sõna kabuhirm ei tunne. See ei ole rahvakeele sõna, vähemasti mitte laiema levikuga rahvakeele sõna, mis oleks murdesõnavara kogumisel esile tulnud. Selle sõna on Wiedemanni sõnaraamatu teisest trükist (Wiedemann 1893: 176) välja noppinud Johannes Aavik ja esitanud oma uute sõnade sõnastikus (Aavik 1919: 24). Sealt saigi alguse kabuhirmu võidukäik eesti kirjakeeles. Kas Wiedemanni sõnaraamatu sõna pärineb mõnelt keelejuhilt või on võetud mõnest XIX sajandi kirjamehe teosest, see küsimus jääb esialgu vastuseta. Mõlemal juhul on tõenäoliselt tegemist omaaegse põgusalt levinud Põhja- või Kirde-Eesti murdekeelendiga, mis eesti keeles näikse olevat pigem pisut äraspidise kuju saanud uuem soome tõlkelaen kui meie keelelisi ürgsidemeid kajastav iidvana sõna. 


\section{leetrid}

Meditsiinitermin leetrid, seletava sõnaraamatu järgi '(laste) nakkushaigus, mida iseloomustab punane laiguline lööve' (EKSS 3: 82), on tänapäeva eesti keeles laialt tuntud sõna. „Eesti etümoloogiasõnaraamat” tõlgendab seda laenuna, mille aluseks on keskalamsaksa sõna bladder, bledder, bledere 'vill, rakk' (EES: 234; tähendustele tuleks lisada ka 'vistrik, mädavill'). Keskalamsaksa sõna pole mulle teadaolevalt nakkushaiguse tähenduses dokumenteeritud, kuid selle ülemsaksa vaste Blatter 'vistrik, mädavill' mitmuse vorm Blattern tähendab ka 'rõuged' (vrd eesti murretest hajateadetena registreeritud tuuleleeted, VMS II: 567), nii et tõlgendus paistab esmapilgul olevat vägagi usutav.

Aga nii kummaline, kui see ka ei ole, ei taha eesti keeleaines selle üsna selgena näiva tõlgendusega hästi sobida. Nimelt on sõna leetrid sõnaraamatutes kaunis hiline nähtus; esialgu esineb samatähenduslik sõna ilma r-ita: 1660 Leedet 'Masern, morbilli', leede [Arbet] 'Masseln [Narben]' (Göseken 1660: 289, 306), u 1710-1730 Letet 'Die Masern', Temma on letes 'Er liegt an der masern', Jubba temma pöddi Letet ärra 'Er hat die Masern schon überbracht' (Vestring 1998: 119), 1732 letit 'die Masern' (Anweisung 1732: 230), 1780 letit (letet) 'Masern', temma pöddis letit ärra 'er hat die Masern überstanden' (Hupel 1780: 204). r-iga leetrid ilmutab ennast seniste $r$-ita sõnakujude kõrval alles A. W. Hupeli sõnaraamatu teises trükis 1818. aastal ning näib, et see polnud tollal veel kuigi laialt levinud: sõnaraamatu eesti-saksa osas on sõnale letred lisatud murdemärgend $J$. (= Järvamaa), saksaeesti osas aga sõnale leetred hoopiski Ob. (= Põltsamaa; vrd Hupel 1818: 120 leted ja 464-475 Masern). Ka XX sajandi murdeandmed näikse viitavat sellele, et leeted $(\sim$ leeded $)$ on sõna varasem, käibelt taanduv või taandunud kuju ja leetrid $(\sim$ leedrid) on uuendus: esimese levik piirdub Põhja-Eesti murdeala kahe vastasservaga (ühelt poolt Kirde- ja Ida-Eestis ning teiselt poolt Lääne-Eesti mandriosas), teise levik on laiemalt põhjaeestiline (VMS I: 420).

Seega näivad niihästi vana kirjakeele kui ka murdeandmed viitavat sellele, et ilma $r$-ita sõnakuju on eesti keeles primaarne. Sellise sõnakuju sidumine keskalamsaksa sõnaga eeldaks aga juba õige mitut püdelal pinnal seisvat oletust: esiteks tuleks oletada sõnalõpulise er-i meelevaldset ärajätmist, teiseks lähtumist alamsaksa sõna reeglipäratust pika esisilbivokaaliga kujust bledere, mille leviku ulatus pole selge (keskalamsaksa käsiraamatus on see sõnakuju esitatud sulgudes, vt Lübben 1888: 56), ja kolmandaks jääks selgusetuks, miks hakati eesti keeles leetrite tähenduses tarvitama alamsaksa sõna, mille samas tähenduses kasutamise kohta alamsaksa keelest endast on raske näiteid leida. ${ }^{1}$ Kõik on ju põhimõtteliselt võimalik ja reegli- ning ootuspäratud arengud pole keeles mingi imeasi, aga kolm niisugust oletust on ühe sõna kohta ikkagi liig mis liig ning paneb alamsaksa laenu võimaluses tugevasti kahtlema.

Näib hoopis usutavam, et leetrid on puhtalt eesti keele pinnal kujunenud sõna. Vähemasti eesti murrete tundjale ei tohiks olla võõrad niisugused dialektismid nagu leet '(valkjas)punane' ja rubid ( ruid) 'rõuged; nahalööve'. Murdesõna leeted lähtub ilmselt üksnes esimesest sõnast leet, kirjakeelne leetrid aga on lühenenud omaaegsest liitsõnast leetrubid ( * *eetruid > leetrid). Mõlema etümoloogiline tä-

\footnotetext{
${ }^{1}$ Alamsaksa vastav sõna on mas(e)le, massele, millest lähtub - võimalik, et läti keele vahendusel (vt Vaba 1997: 133) - kolmest Saaremaa kihelkonnast registreeritud murdesõna mastlid 'leetrid' (VMS II: 19). Nagu ülaltoodud näidetest näha, on seda sõna omal ajal kasutanud ka Heinrich Göseken sõna leede vastena.
} 
hendus on 'punane lööve, punased lööbelaigud'. XX sajandi murdekogudest puuduvat liitsõna leetrubid ei tarvitse seejuures meelevaldselt teoretiseerida, vaid see on fikseeritud Wiedemanni sõnaraamatu artiklites lète ja rubid (Wiedemann 1869: 544, 1088; Wiedemann 1893: 492, 985), esmakordselt aga 1813. aastal koos sõnaga letrid Valjala pastori A. H. Schmidti leksikaalsetes lisandustes A. W. Hupeli keeleõpetuse esitrükile (Beiträge II: 104).

Asjaolu, et nii leet kui ka rubid on Lääne-Eesti, valdavalt Saarte murde sõnad (vt VMS I: 420, VMS II: 344), neist kujunenud haigusenimetused leeted ja leetrid aga on märksa laiema põhjaeestilise levikuga (Lõuna-Eesti murretes on sama haiguse nimetus läätsä), tõstatab küsimuse, kas leet ja rubid olid varem laiemalt tuntud, kui seda kajastavad XIX sajandi sõnaraamatud ja XX sajandi murdekogud, või ongi leeted $\sim$ leetrid kujunenud Lääne-Eestis ja valgunud sealt mujale Põhja-Eesti alale. Sellele küsimusele usaldusväärse vastuse andmiseks puudub aga paraku materjal.

\section{üllitama}

Kirjakeeles loodud uudissõnade elukäik on huvitav: mõnega on nii, et algul ei saa vedama, pärast ei saa pidama. Juba 1920. aastate algul loodud üllitama konutas pikka aega varjusurmas, aga ühtäkki on ta nii populaarseks saanud, et pole hoo ega hoobi vahet: üllitatakse raamatuid, ajakirju, alastikalendreid, CD-sid, singleid, videoid, laule, hittlugusid, manifeste ja mida kõike veel. See sõna vajab väikest tekkeloolist kommentaari, sest paistab, et siin pole keeleteadlastelegi asi alati päris selge.

„Eesti etümoloogiasõnaraamatus” on sõna üllitama juurest viidatud märksõnale üle, mille all on tõdetud: „üllitama on 1920. aastatel kirjakeeles loodud reeglipäratu tüvemuutusega tuletis.” (EES: 636). Etteruttavalt võib öelda, et kui väide reeglipäratust tüvemuutusest välja arvata, on käsitlus iseenesest paikapidav, aga paraku ilmselt isegi keeleteadlaste jaoks liiga kidakeelne, sõnaraamatu tavakasutajast rääkimata. Asi vajanuks lähemat selgitust, sest sageli on väidetud, et sõna üllitama on Johannes Aavik laenanud soome sõnast yllyttää 'ässitada, üles kihutada, õhutada'. Ja tõepoolest, kui lööme lahti Aaviku „Uute sõnade ja vähemtuntud sõnade sõnastiku" teise trüki, siis leiame sealt märksõna yllitama ja seletuse 'ässitama, kihutama' (Aavik 1921: 142). Märgend se osutab, et sõna on laenatud soome keelest ja alles ettepaneku staadiumis, s.t uhiuus ja pole veel käibele tulnud. Kõik paistab justkui selge olevat, aga kas ikka on? Kuidas on võimalik, et tähendusest 'ässitama, üles kihutama' saab asja ees, teist taga 'avalikkusele kättesaadavaks tegema, publitseerima'?

Tegelikult ei tulnud Johannes Aaviku pakutud soome laensõna eesti keeles üldse laiemalt käibele. Praegune üllitama lähtub hoopis teisest, konkureerivast ettepanekust. Õigusteadlaste Selts Tartus rakendas 1920. aastate algul tööle oskussõnade komisjoni, mis asus korrastama eesti õigusteaduse termineid. Keeleteadlastest osales komisjonis J. V. Veski. Töö tulemusi üllitati jaokaupa ajakirjas Õigus, mille 1922. aasta teises numbris ongi sõnastiku „Tsiviilseadustiku oskussõnad" järjekordses osas vene обнародовать, saksa publizieren vastena välja pakutud üllitama. Sõnastiku kommentaaris on napisõnaliselt öeldud, et üllitama on tuletatud ,juurest „üld”, seega üldiselt teatavaks tegema, kuna „üldima” tähendaks üldiselt teatavaks saama" (Karlson 1922: 62). Paneme tähele: ühelt poolt üldi- 
ma tugevaastmelise tüvega ja teiselt poolt üllitama nõrgaastmelise tüvega. Sõna looja(d) on lähtunud vanadest astmevahelduse reeglitest, mille järgi lahtisele silbile eelneb tugev ja kinnisele nõrk aste, ehkki tänapäeva keelekasutajale pole need seosed enam nii selged ja sõna üllitama ta arvatavasti üld-tüvega ühendada ei oska.

Oskussõnade komisjon on Johannes Aaviku uudissõnade sõnastikku hoolega kasutanud ja sealt sõnu ammutades korrektselt Aavikule viidanud. Kõnealusel juhul viide puudub. Ehkki võib oletada, et see sõna on Aaviku väljapakutud soome laenust inspireeritud, pole see ikkagi enam seesama sõna, vaid komisjonis loodud täiesti teistsuguse tähendusega uudistuletis.

\section{Kirjandus}

A a vi k, Johannes 1919. Uute sõnade sõnastik. Sisaldab üle 2000 uuema ja haruldasema sõna. Tartu: Istandik.

A a vi k, Johannes 1921. Uute sõnade ja vähem tuntud sõnade sõnastik. Teine parandet ja suuresti täiendet trykk. Tallinn: A. Keisermann'i kirjastus.

Anweisung 1732 = Kurtzgefaßte Anweisung Zur Ehstnischen Sprache. Halle.

Beiträge II = Beiträge zur genauern Kenntniß der ehstnischen Sprache. Zweites Heft. Pernau, 1815.

EES = Eesti etümoloogiasõnaraamat. Koostanud ja toim Iris Metsmägi, Meeli Sedrik, Sven-Erik Soosaar. Peatoimetaja Iris Metsmägi. Tallinn: Eesti Keele Instituut, Eesti Keele Sihtasutus, 2012.

EEW = Mägiste, Julius. Estnisches etymologisches Wörterbuch. Bd. I-XII. Helsinki: Finnisch-Ugrische Gesellschaft, 1982-1983. (II trükk: 2000.)

EKSS $=$ Eesti keele seletav sõnaraamat, I-VI. Tallinn: Eesti Keele Instituut, Eesti Keele Sihtasutus, 2009.

EMS = Eesti murrete sõnaraamat. Tallinn: Eesti Keele Instituut, 1994-.

G ö s e k e n, Heinrich 1660. Manuductio ad Linguam Oesthonicam. Anführung Zur Öhstnischen Sprache. Reval: Gymnasij Buchdr.

H u p e 1, August Wilhelm 1780. Ehstnische Sprachlehre für beide Hauptdialekte den revalschen und den dörptschen, nebst einem vollständigen ehstnischen Wörterbuch. Riga und Leipzig: Johann Friedrich Hartknoch.

H u p e l, August Wilhelm 1818. Ehstnische Sprachlehre für die beyden Hauptdialekte, den revalschen und dörptschen, nebst einem vollständigen ehstnischen Wörterbuche. Mitau: J. F. Steffenhagen und Sohn.

K a r l s o n, Ferdinand 1922. Seletused eelseisvate oksussõnade juurde. - Õigus, nr 2, lk 57-62.

Ke t t u n e n, Lauri 1917. Virolais-suomalainen sanakirja. Helsinki: Otava.

L ü b b e n, August 1888. Mittelniederdeutsches Handwörterbuch. Norden-Leipzig. (Faksiimiletrükk: Darmstadt: Wissenschaftliche Buchgesellschaft, 1965.)

R a u n, Alo 1982. Eesti keele etümoloogiline teatmik. Rooma-Toronto: Maarjamaa. SKES I = Y. H. Toivonen, Suomen kielen etymologinen sanakirja I. Helsinki: Suomalais-Ugrilainen Seura, 1978.

SSA = Suomen sanojen alkuperä. Etymologinen sanakirja I-III. Helsinki: Suomalaisen Kirjallisuuden Seura ja Kotimaisten kielten tutkimuskeskus, 2001.

SÕS I = Suur õigekeelsus-sõnaraamat I. Tartu: RK „Teaduslik Kirjandus”.

T u k s a m, Gustav, M u u k, Elmar 1939. Saksa-eesti sõnaraamat. Tartu: „Kool”. 
V a b a, Lembit 1997. Uurimusi läti-eesti keelesuhetest. Tallinn-Tampere: Eesti Keele Instituut, Tampereen yliopiston suomen kielen ja yleisen kielitieteen laitos.

Vest r ing, Salomo Heinrich 1998. Lexicon Esthonico Germanicum. Toim Ellen Kaldjärv. Tartu: Eesti Kirjandusmuuseum.

VMS = Väike murdesõnastik I-II. Toim Valdek Pall. Tallinn: Valgus, 1982-1989.

W i e d e m a nn, Ferdinand Johann 1869. Ehstnisch-deutsches Wörterbuch. St. Petersburg.

W i e d e m a n n, Ferdinand Johann 1893. Ehstnisch-deutsches Wörterbuch. St. Petersburg. 